\title{
A Qualitative Investigation of Workplace Bullying Construction: A Case Study on Hikma Pharmaceutical Company in Jordan
}

\author{
Naser Khdour \\ Business Administration Department, Philadelphia University, Jordan \\ E-mail: nkhdour@philadelphia.edu.jo
}

Received: Jan. 30, 2017

Accepted: Feb. 20, 2017

Published: April 1, 2017

doi:10.5296/jmr.v9i2.10666

URL: https://doi.org/10.5296/jmr.v9i2.10666

\begin{abstract}
The study aims to investigate different ways that help the administrative consultants to construct concepts of bullying within a workplace environment. The study recruited administrative consultants from Hikma Pharmaceutical Company in Jordan through semi-structured interviews. The data obtained from the interviews was analyzed using NVIVO package. The results showed that management-oriented policies, lack of consultants' power, and the pressure built within the organization for protecting managers have made workplace bullying a complex problem. Despite the consequences of bullying, the individuals at workplace tend to use different interpretive mechanisms to validate the manager's behavior. Bullying among the colleagues within a workplace environment is considered as an inter-personal association between the manager and employee as the victim's response to management and performance work practices. Therefore, the results concluded that behavior of a manager and an employee is not really constructed by administrative consultant as bullying within the workplace environment.
\end{abstract}

Keywords: Workplace Bullying, The construction of bullying, Administrative consultant, Hikma Pharmaceutical Company, Jordan 


\section{Introduction}

The behavior of people at workplace is always a major concern for the organization. The organizational behaviors that are functional and desirable to achieve mainly include commitment-related behavior, organizational citizenship behavior, and prosocial behaviors (Aleassa \& Megdadi, 2014). The repeated practices and actions directed towards an employee that are unwanted are termed as bullying. The bullying behavior is humiliating for the victim and may even interfere with their job performance in an unpleasant working environment. The investigation of workplace bullying construction is important as these behaviors are likely to contribute to organizational effectiveness, negatively (Glambek et al., 2018). The victims of bullying face mental and emotional harm, career damage, and physical illness. It may even affect the organization negatively by reducing its profitability and productivity due to loss of valued customers (Aleassa \& Megdadi, 2014).

The administrative consultants play a significant role in identifying bullying taking place within an organization. These individuals are responsible for handling the claims by employees regarding the bullying behavior (Salin, 2009). Workplace bullying remains a serious issue for administrative consultants within an organization, because it significantly affects financial management of the organization. Bullying behavior is harmful for the victim physically as well as psychologically. The employees believed that managers use power of their position to gain more success within the organization by bullying others. It can be said that the unfair organizational practices are also termed as bullying. The organization itself plays an important role in depersonalizing bullying behavior that occurred between the workers. The association between organizational practices and doubtful legitimacy is the main focus of participants' interpretation of organizational bullying.

Work place bullying is common in the private-sector institutions that are recognized as high-risk settings for workplace bullying. The examination of private-sector ethos is of great relevance in major parts of the world, as it is responsible for providing vital services. (Hutchinson \& Jackson, 2015). The reports of bullying challenge the range of behaviors, having significant impact on the main notion of bullying. Regardless of distress feeling, the bullying behavior needs to be stemmed from perceived unfairness and injustice of the organization practices. The setting for the research is within the Hikma Pharmaceutical Company. The company was founded in Amman, Jordan, in 1978. Hikma's website (hikma.com, 2014), reported that they market, manufacture, and develop, pharmaceutical products consisting of generic and in-licensed and branded and non-branded products. The company conducts its operations in North Africa, Europe, the Middle East and the United States. As at 2013, the company had a twenty-three per cent growth in revenue. Hikma is a listed company on the Financial Times Stock Exchange (FTSE), top 250 companies, at four in the list. The company had 7,067 employees, including, of which1800 sales representatives working in the four regions where the company operates. They have strength in their marketing teams, brand recognition and customer loyalty and satisfaction(hikma.com, 2014).

The experiences of bullying by the victim involved inaction, blaming the victim, and denial. The impact of bullying behavior on a victim depends on how the victim perceives it. At times, 
the responses given by administrative consultant are perceived as an addition to the bullying behavior, which increases the exacerbation of its negative impact (D'Cruz, 2014). However, the studies providing evidence of how the employees working as administrative consultant explain the bullying behavior are scarce. Previous studies conducted by Salin (2008) and Salin (2009) have investigated the responses followed by administrative consultant to claim the bullying behavior; however, none of the studies have investigated what establishes bullying behavior to administrative consultant. Therefore, the present study has contributed to understand how administrative consultants perceive the claims of bullying at workplace, including the impact of those claims and their response towards such claims. Therefore, the study aims to investigate the constitution of bullying by administrative consultant. It has evaluated the possible consequences behind the actions performed by these consultants through providing insights on different social constructs associated with bullying behavior.

\section{Study rational}

Bullying is an expensive and a prevalent issue for both employees and organisations and consequently, it is an important issue for academic research (Mikkelsen, 2003). The experiences of the victims of bullying reported by the administrative consultants in research by Ferris (2009) involved blaming the victim, denial and inaction. There is a scarcity of research evidence on how employees working as Administrative consultants define the behavior of bullying (Salin, 2008), however, Ferris' results indicate that victims and might well have different perceptions of bullying.

Research by Einarsen, Hoel, Zapf and Cooper (2003) indicated that employees interpret administrative consultants actions in response to occurrences of workplace bullying not as effective or positive actions. Responses to both interviews and questionnaires by victims indicated that they tended to either be disbelieved or inviting bullying behavior by work colleagues, management, administrative consultants and management. Victims of bullying, for instance, perceive administrative consultants and managers make inconsistent responses with claims of bullying in terms of policy on how to respond to the issue (Ferris, 2004), or they deny an issue is present (Ferris, 2009), or they do not respond with any action (Lutgen-Sandvik, 2008), or they attribute it to a clash of personalities (Keashly, 2001), or they accuse victims of being too sensitive (Vickers, 2006). Harlos (2001) referred to these types of responses as not listening or having a deaf ear to the problem, indicating that this exacerbates the adverse impact of having experienced such behaviour. Consequently, the administrative consultants responses may be perceived as additional bullying, increasing the exacerbation of the impact felt by the victim (D'Cruz and Noronha, 2010).

Work by Salin $(2008,2009)$ has investigated both the actions and responses that administrative consultants might follow in claims of bullying behaviour, however, no published research has explored what actually constitutes bullying behavior to administrative consultants, and the factors that explain or determine their particular actions. As a consequence, the research questions posed, and the answers to those questions, in this research will help to contribute to an understanding of specifically how the administrative consultants in this research construct and perceive claims of bullying a work and what 
particular elements impact on when, and how they respond to such claims.

\section{Research aims and objectives}

1. To investigate the administrative consultants constitution of bullying

2. To investigate the possible explanations or determinants of the administrative consultants actions.

3. To provide an insight on the various social constructions of the term bullying.

\section{Research question}

How do administrative consultants construct bullying in the workplace?

\section{Research contribution}

1. As far as the researcher is aware, this research is the first study on bullying in the workplace and how administrative consultants construct bullying in their place of work, specifically the pharmaceutical company called Hikma.

2. This research has a unique opportunity to investigate the topic of bullying in the workplace at one specific organisation. Furthermore, it will explore examples, of any activities or behaviour that impacts on workplace bullying. It will also explore and analyse the various ways in which both administrative consultants and employees comprehend the issue of bullying in the workplace.

3. This research will consider the different viewpoints to investigate the daily reality of bullying at Hikma. Results to this particular element of the research will improve management practices at Hikma when it responds to a variety of constructions of bullying.

\section{Literature Review}

\subsection{Bullying Behavior and its Nature}

Any behavior resulting in negative impact for the victim is characterized as bullying behavior (Zapf \& Einarsen, 2005). The bullying behavior may be social, isolating, or work based; for instance, giving excessive workload or withholding the significant knowledge. It tends to develop constant criticism by spreading rumors (Einersen et al., 2003). These behaviors are systematic and heighten gradually. The association between administrative consultant and victim develops on the basis of power imbalance to a certain extent that are retaliated by the victims. The bullying behavior arise from one or more possible factors that is associated with position of management (Bowling \& Beehr, 2006).

\subsection{Critical Discourse of Organizational Bullying}

In the critical discourse, bullying is termed as a management practice that is effectively obtained to an increased level of performance profit (Rhodes et al., 2010). Critical discourse of organizational bullying develops as a result of organizational practices, which facilitate the bullying behavior. It is made apparent by daily processes and structures of an organization. The critical discourse factors are based on performance management for the employees, who 
are capable to resist the bullying behavior and its consequences (Rhodes et al., 2010). The structure of the organization is framed on the power dynamics that exist in the capitalist and managerialist discourses. The discourses that are involved in the development and maintenance of power occurring between organizational groups involve the social practices. Performance and disciplinary practices, and organizational practices (Liefooghe \& MacKenzie, 2010). The process of legitimacy of social influence embodies power within the individuals, which is carried out through the discourse of organizational practices providing advantage to the management.

\subsection{Bullying Constructed by Organization}

The policies implemented within the organization affects how the administrative consultants work in recent years. The two ways that are specified for individual notions of bullying to enter an organization are; through publishing material regarding bullying and through guidance text (Liefooghe \& MacKenzie, 2010). At times, the victims themselves are blamed for making issue and according to the public they are the ones, who are at fault.

\subsection{Bullying Constructed by Victims}

The investigations of bullying experiences of victim demonstrated that these alleged bullies are mostly the managers or the supervisors. These individuals have an authority over the victim that is misused. It has been reported by the victims that their experiences mainly comprised of discrimination and harassment that stems from the accusations of poor work performance. Mostly, the victims complain that they do not receive any support from the administrative consultants, which escalate the bullying behavior (Ferris, 2009). It is because; at times, the administrative consultants ignore the victim's claims; however, according to the victims these consultants are responsible for giving managerial support. It has also been stated that administrative consultants identify the victim as trouble maker that results in increase of bullying behavior towards the victim (Keashly, 2001).

\subsection{Bullying Constructed by Administrative consultants}

A study conducted by Baillien et al. (2009) mainly concentrated on the way in which the organizational representatives (administrative consultants) agree for the construction of a specific manner. The individual factors including; unresolved conflict, coping styles, work design, and destructive leadership have been used to evaluate the impact of workplace bullying. Bullying, within an organizational context comprises of individuals behaving inadequate with other employees. The company itself is considered to be a facilitating backdrop; one that possibly triggers, motivates and enables bullying. The depersonalized practices within the organization are observed as unjust and unfair to the employee.

\section{Research Methodology}

This paper has adopted a qualitative approach in its attempt to consider a few of the methodological limitations hindering bullying research using a survey-based tool (Parzefall and Salin, 2010; Keashly and Jagatic, 2003). This approach has been considered to be a suitable tool for meeting the previously stated objectives and aims and to respond to 
questions that may arise, due to its inductive, interpretive and exploratory nature. The Hikma Pharmaceutical Company was the focus of the study, with collected data from seventeen participants including employees and their semi-structured interviews. NVivo was utilised as a suitable programme for data analysis and to organise the various themes of the data. This combination of a review of relevant literature, alongside fieldwork, was used so as to conduct a thorough investigation into bullying in the workplace. The qualitative approach was utilised throughout the course of this research, with the semi-structured interviews forming the bulk of the collected data. These involved the participants offering their various daily experiences, their different understanding and perspectives of bullying in the workplace of the Hikma Company. The transcripts of these interviews, both practically and theoretically, provided information about the manner in which 'ordinary people construct meaning in relation to a particular topic' (Willig, 2008a: 114). Although the interview offers information of an interaction between interviewer and interviewee (Rapley, 2001), the very involvement of another individual working as an interviewer can frequently result in the discovery of valuable data which may otherwise have been omitted (Griffin, 2007), and this was the reason behind participants being selected for interview, plus the fact that each one was involved in an HRM role that was concerned with bullying cases.

The term 'saturation' is one that determines the participant numbers, as saturation can be said to be reached when there are no more changes to arising themes after examination, nor any more new insights (Guest et al., 2006). Indeed, Guest et al., (2006) using a purposive, theoretically-defined sample, argued that saturation can be reached after engaging in around twelve interviews.

The interviewees had the nature and purpose of the research explained to them over the telephone before the interviews took place and each one was requested to find around forty five to sixty minutes for this activity that occurred in a quiet office. The participants all agreed that the interview could be recorded by the use of a digital voice recorder in order to help with the analysis of the emerging data.

All the emerging data was analysed by use of a line-by-line method and was not separated into different sections. Sentences and phrases were coded when they were observed to represent examples of particular stages (Silverman, 2005).

\section{Findings}

\subsection{Administrative consultant Handling Bullying Behaviors}

Majority of the administrative consultants, throughout the interviews demonstrated complexity of handling claims. It is difficult and challenging for these consultants to ascertain sufficient material to make a specific judgment about the bullying behavior. A respondent stated that;

When a person is countered for bullying, at times they simply say that they didn't realize at all that was somewhere near to bullying.The individual has no evidence to proof that he has experienced bullying. It is hard if not impossible to handle such situations.(ACB2) 
Respondents rise up the issue of not having a direct source of how to deal with bullying claims. There is no white or black answers as bullying claims are not published in cases and shared with employee. However, the solution was to depend on their personal experience and personal Judgment. According to a respondent;

At times situations are impossible to handle because you have to pass on personal judgement. It usually gets difficult as bullying cases are not mentioned in literature work (ACB3)

Interestingly other participants have alluded to the shame culture as long as organizations are working within a conservative culture. There are lot of norms and tradition surrounding the Jordanian business environment. It is hard to isolate these factors from business.

It is a complicated issue as we have here and everywhere the shame culture. You will feel that people start talking about you or you are even an odd person... we did not get to use to speak it up (ACB1)

Toward something else, some participants included the Jordanian tribal life with understanding and handling bullying. Tribalism is a vital part of Jordan. All employees are proud of their tribes. Whilst tribalism has been described as informal channel that interfere any business, the possibility to avoid such issue is a hard mission. However, the scenario getting worse in case managers come from big tribes, then bulling could be one part of their personalities. Generally, countries have different rules and regulations that govern bullying, more precisely the western countries but the case is different in the developing countries in terms of having these rules and regulations against bullying but applying them is another issue.

Before asking me how do I define bullying let me tell you that bullying for me is totally linked with tribalism. Don't be amaze, Tribalism give power to anybody. No one can touch you as you have somebody behind you. He will support you and find solutions to your entire mistake despite you did the mistakes. (ACB5)

There is no comparison between Arab countries and Western countries in term of bullying policies and procedures. They are developed but us still developing. There is no value of these written rules and even code of ethics if the top management don't believe in them or somebody from outside the organization who got power can change the case...I am disappointed from this. (ACB8)

Administrative consultants have to bear a lot of considerations while they deal with bullying. Sometimes different people from outside the organization try to interfere the bullying situation therefore, in such cases administrative consultants may not be fair, on the other hand, they feel uncomfortable especially when investigate a case of bullying and the investigation results turned out to have an effect on employees career and their career path. According to a respondent;

I am totally uncomftable with bulling investigation cases. Your decision is affecting employee's future and might have a bad influence on the social aspect of their life, their 
career in general and their promotion, their career path and so many interrelated issues that really make you think twice before doing anything, we are more emotional... thinking in our hearts. (ACB9)

Some participants have shared their personal experience on the big expectation while they handling bullying claims. In some cases employees try to put them under pressure of what is called in Jordan as "Wasta". It means simply being bias, however, in other cases administrative consultants being asked directly to solve the bullying issue immediately. Administrative consultants have to make it clear that investigation should be according to rules and regulations, however, the main mission here is just to investigate and reach to a conclusion about the issue but it Is not the final decision as after that there are so many procedures and other managerial level will take the final decision. It was clear from the interviewees that there is unaware and misunderstanding of this issue completely. The premises of this that the concept is still vague, the written rules not applicable completely, the shame culture is still there. Employees don't know how to report bullying.

Sometimes, it is unbelievable. They have a bigger expectation. They think you can do everything and there are no policies and procedures. My role is to investigate and give results other managers will take the next step. They ask me to interfere in another word they ask for "Wasta". Wasta for me is absolutely the main reason for organization corruption. It lets people take other people rights, and try to escape from punishment. (ACB12)

From employee's perspectives, many participants have focused on the new ways of doing the jobs. It is clear that team work is dominant now. Employees have highlighted the issue of MBO (Management By Objectives) thus, they have to work hard to reach these objectives, they are fighting and they are under pressure.

The culture of organizations has completely changed. We are working under management by objectives. Our performance appraisal is depending on that, we are under pressure, not only me all of us. Performance appraisal is the bottom line of our work our promotion and money raise depend on that. We should achieve our setting goals otherwise we will panic at the end...it is hard working environment life, we should survive. (ACB16)

A great emphasizes has been placed on performance appraisal. Managers want employees to work with high capacity, they want to increase productivity, and something like bullying will waste their time, effort and increase cost.

"Workplace environment is effected due to the increase in bullying as it is resulting in degradation of performance. As well as takes a lot of valuable time. We work to keep our performance appraisal high, our salaries and promotions are also a concern. All of us I mean all parties should work to reduce bulling as long as such issue will have a bad effect on both parties the organization and the employees."(ACB17)

\subsection{Work Conflicts as a Result of Bullying Claims}

The study has evaluated the way in which administrative consultants interpret and construct the association between manager and employee regarding the bullying claims. The 
consultants have to handle a great number of bullying claims. According to a respondent;

The pressure built on an individual create a lot of problems by creating stress and tension. At times, these clashes occur between two or more people. (ACB10)

Conflicts may occur on the basis of unresolved issues. In most of the cases, both parties are equally responsible. It is observed that the conflicts and claims usually grow from small insignificant incidents:

The hypertensive individuals, who react abruptly, do not like anything that an employee performs. It is not helpful for the environment at all. These types of cases are not easy to resolve, as compared to the conflicts that arise between the management and the employees. (ACB13)

The Jordanian work culture has been described as hard. Employees and managers are coming from different locations and they have different personalities and opinions about everything. At any stage of work life employees can become a pretty to bullying just because simply of a bad feeling toward somebody such as somebody being seen as an arrogant person.

At times, the conflicts do not occur on the basis of some major issue but sometimes it's just two people clashing about how things should be done or they start looking for each other as enemies and have bad feeling toward each other or alleged a person that he or she is an arrogant person, so I feel it is really trivial issues not major ones. (ACB5)

\subsection{Bullying Claims by the Administrative consultant}

The study has discussed bullying claims pointing towards the managers. However, the administrative consultants do not consider these cases as bullying when the employees blame their own manager for bullying. According to the respective professional, the performance of victim is the main cause of bullying behavior by the managers. In most of the cases, the employee does not work in accordance to achieve their targets. Their work is not in compliance with the job objectives as well as they exhibit non-serious attitude towards work. In the same context, one of the respondents stated that;

When you put some employees under pressure to perform, you want to make them efficient, to achieve goals with low waste, later on you just discover that they took it as bullying. Which bullying they are talking about? This is your Job! You are here to deliver! and I am sorry if I say we pay you and we expect from you a hard work. It is hard to find me calm down if my employee did not put the max of their abilities at work. (ACB6)

Some employees are described as "not easy" as they claim bullying a result of employee's poor contribution towards performance management. In most of the cases, the employee was not able to meet manager's demands properly. Therefore, when such claims come forward, the victim was expected to be able to prove their case. According to a respondent;

Some of the employees are not easy especially when they claim for bullying when they want to avoid doing a particular task or start realizes their poor performance. (ACB11) 


\section{Discussion}

The study has examined the way in which administrative consultant consider the bullying behavior in the workplace. The findings have shown that bullying is termed ambiguous and difficult to deal with the pressure generated by management. The study has provided further insights about how antithetical missions seek for broadening the debate on dynamics of failures within the private-sector institutions (Hutchinson \& Jackson, 2015). The internal competition, performance management, and control of organization are altered by emphasizing on the employee performance (Beale \& Hoel, 2011).

The interview session clearly drew the negative discourses within their professional material through proper training. It gives rise to certain queries to show whether the changes are apparent in the practices of administrative consultants. The claims of bullying are rationalized and interpreted for constructing an individual position with regards to the victim. On the basis of the current economic status of Jordan, administrative consultants tend to intensify the domain of performance management. The duty performed by administrative consultants is driven by targets and various performance cultures. The main role of administrative consultants is to support employee management and improve their performances. In order to comply with the goals and strategies of the organization, it is necessary to rationalize the manner in which the organizations change. It is clearly justified on the basis of performance and productivity of the employee.

Bullying is considered as a prevalent problem among employees, working in a single organization that comprises of direct and indirect verbal acts. It results due to hierarchy, power, work environment, discrimination, and silent victim. The recruitment and retention of employees in Jordan is at high risk due to overlooking of triggers related to bullying behavior. The administrative consultants are capable of predicting the unethical behavior and psychological ownership of the employees by mediating the association between bullying and unethical behavior (Aleassa \& Megdadi, 2014). The results have clearly suggested that workplace bullying is a major risk factor for imposing adverse effects; therefore, the main agenda of administrative consultant is to prevent this practice in workplace environment.

Bullying has a negative impact on the employee that significantly affects decision of an individual to get involved in unethical behaviors, as they may cause severe economic losses. The administrative consultants get involved in the development and adoption of intervention strategies to restrain workplace bullying, as it is likely to bring economic benefits for the organization. The organizations where the culture tolerates and normalizes such behavior do not give much importance to these behaviors and its negative consequences (Rhodes et al., 2010). On the other hand, employee also needs to be confident enough in reporting the bullying cases, without any fear of repercussion. Administrative consultants need to enact and enforce policies that delineate bullying behaviors line in line with a discipline system.

The administrative consultant plays a critical role in constructing positive behaviors among employees. A standard methodology is adopted, which prohibits bullying at the workplace. The administrative planning identifies the requirement and needs of the employees. It is a fact that the presence of aggressive and violence incidents at the workplace put the integrity of the 
manager at stake. In scenarios where the bullying incidents are occurring on regular basis, the manager feels the pressure to report the case to top management. According to Fox and Cowan (2015), administrative consultants should respond effectively to the complaints and queries of the employees. An effective complaint-based system should be present within the organization. The administrative consultants should define the definition of bullying in the company's code of conduct policies. Furthermore, the employees should be provided guidance about reporting bullying cases to the management.

The Hikma Pharmaceutical Company should incorporate effective policies for preventive bullying and harassment at workplace. The employees should be treated fairly, who have been a victim of bullying. Furthermore, the company should adopt a policy, which ensures that the employees are free to report bullying cases to the line managers. A standard framework should be incorporated by Hikma Pharmaceutical Company, so that the employees can feel that the company is taking effective measures for protecting their fundamental rights.

Desrumaux, et al. (2015) has examined the behaviors and emotions among individuals on the victims. The individuals, suffering from bullying issues, feel insecure in many situations. Furthermore, the feeling of depression, loneliness, and anxiety is also developed. It is necessary for an organization to deal with the victims, suffering from bullying on the basis of equality. The findings revealed that the judgment of bullying incidents, occurring within an organization is carried out on non-equality basis. In most of the bullying cases, the perpetrators were punished for their acts. The support was provided to the individuals by the company, who suffered from antisocial emotions and behavior.

The diversified personalities and behaviors of the individuals working within an organization may encourage bullying. Some of the individuals are naturally aggressive in their behaviors and attitudes. Therefore, these types of people are more likely to interact with their peers and subordinates in a harsh or rude manner. It is the responsibility of line managers to interact with these types of individuals on a regular basis. One to one private sessions can be conducted for resolving their disputes and conflicts within the workplace environment. The aggressive attitude shown by the individuals is due to the fact that their opinions and viewpoints are not valued within the organization (Magee et al., 2015). The line manager should make the individuals realize that the management respects the viewpoint of each and every individual within the organization. An interactive group discussion between the team members can contribute towards reducing the tension at workplace.

The increasing number of bullying and aggression cases occurring within an organization creates a negative impact on the performance of employees (Hewett et al., 2018). The workers feel demotivated due to the presence of aggressive and violent behavior at workplace. It is necessary for the organizations to properly document the bullying cases and their impact on the overall performance of company. Bullying is a major concern for small and large size corporate organizations, and it is effective for the productivity and efficiency of the employees. The project manager can also play a role in reducing bullying cases. There should be regular interactions between the employees and management. Furthermore, the employee 
should be allowed to report bullying behavior and attitude to the top management.

Sometimes, the administrative consultants do not have the authority or power to resolve the bullying issues faced by the employees. It is not a responsibility of the manager to deal with bullying cases. The top authorities within an organization should work towards formulating a standard policy for addressing bullying cases. The ethical codes of conduct must be implemented in an organization. Serious action should be taken against the perpetrators, so that the bullying cases at workplace can be reduced. Organization should involve all the stakeholders in formulating a long-term policy. Opinions of the employees should also be considered in developing codes of conduct.

The shouting events, occurred within an organization, are sometimes ignored by the top management. For instance, appropriate action is not taken in scenarios, where indecent behavior has been shown. The managers are sometimes not held responsible for their misconduct. The top management and high authorities should be made fully aware about the inappropriate behavior used by the line manager. The bullying issues faced at peer to peer level should also be addressed by the top management.

The bullying events in some scenarios occur due to over sensitive nature of the employees. Such an employee or worker does not agree with the organizations policies. In such a scenario, a small issue or problem can turn into a bullying incident. The bullying cases between employees are easier to manage. The manager should make the employees realize about the organization values. A private meeting between the employee and consultant can contribute towards resolving the conflict-based situation.

The increased work pressure or high targets imposed by the organization on the employees can transform into bullying incidents. The employees are likely to show negative emotions or behavior in scenarios where the consultants highlight their weaknesses in front of the top management. The expectation of the organization is raised when an employee gains relevant experience or skill. The bullying situation may occur as the employees fail to understand that the employee is liable to fulfill the targets sets by the organization.

Sufficient support should be provided to the managers by top executives in dealing with bullying cases. The higher authorities should understand the stress levels of managers in handling inappropriate employee behaviors and attitudes (Harrington et al., 2015). In reporting bullying cases, the victim should be able to provide the management with concrete evidences. The false claims of bullying and harassment from the employee should be dealt with strictness by the top management. Proper investigation of the claims should be conducted before deciding on the line of action.

Bullying has emerged as a major issue for corporate organizations and businesses. With the advancement of technology, the bullying incidents can occur in a variety of ways. Bullying or aggressive behavior can be delivered in the form of text or video message. In the modern era, the companies need to innovate in developing strategies for handling bullying incidents. The organizations should consider all the technological factors before formulating an effective policy. Policies should be implemented to prevent online bullying and harassment. The focus 
of the top management should be on protecting the fundamental rights of employees. Effective reporting system should be established within the organization. It will contribute towards decreasing the abusive incidents at workplace.

The non-verbal and verbal abuses at workplace have become a problematic area for the management. Often times, it has been observed that the organization lacks adaptation of standard policies for preventing bullying between the employee and the manager. An equity-based system should be established within the company, where every individual is treated fairly. It is the responsibility of top executives to formulate effective policies; so that every employee feels safe and secure in performing their duties. An unsatisfied employee can create a negative environment within the organization. The concerns and issues of the employees should be addressed and dealt effectively. The employees should be taken into confidence before incorporating ethical policies at workplace. It is the responsibility of both employee and consultants to maintain healthy environment in the organization.

\section{This research Limitations}

The results are limited due to small sample size as a result of dependency on a single case study. However, it has provided a holistic account of an empirically rich study design. The study has not addressed all the organizational and individual reasons concerned with the bullying behavior. This type of qualitative analysis method helps in determining the sample size through a certain number of instances. The sample saturation within this study was attained after twelve interviews.

\section{Conclusion}

The results have provided evidence for the presence of workplace bullying experienced by the employees, who sought to mingle in the challenging environments. This study serves as a starting point to conduct further research in the Arab region. Administrative consultants are not eager to consider specific bullying behavior and the affected individuals usually report that these consultants deny their claims of bullying, take no action, and blame the victim only. It has shown that administrative consultants appear to construct incidents of bullying in an entirely different way. These consultants play the role of a manager for improving the performances of employees working in a specific organization. The workplace bullying is becoming a serious concern for the organizations. The role of consultants and employees is necessary in reducing the bullying incidents. Consultants should understand the concerns at the earliest to avoid various complications. A common platform should be provided to the employees for reporting the bullying cases. Employee; on the other hand, should also understand the limitations in dealing with bullying cases. An effective policy or framework can be developed through collaboration with all the stakeholders. The employees' feedback and suggestions should also be incorporated in formulating an ethical code of conduct.

The consultants face higher level of pressure from the top executives in dealing with bullying and harassment cases. Sufficient support and guidance should be provided to the consultants from the top executives, so that any inappropriate situation could be handled effectively. The victim should be provided with an opportunity to express the viewpoint in front of the 
management. Any false claims and allegations levied by the employee should be dealt strictly. All the facts and evidences should be examined before making any judgments. Reviewing the point of view of all the parties would be helpful for the consultants in getting to a correct decision. The manager of victim plays a significant role in shaping the views of administrative consultants. However, the consultant tries to look for another reason for the underperformance of the bullied victim. They tend to respond and interpret the current situation as a member of performance-management. The results have shown that administrative consultants construct a manner to get through the claims by mediating between the identified peers. The company should address the problems faced by the employees. An accountability system should be established in the company. Serious actions should be taken against the perpetrator irrespective of the designation and status in the organization. An equity-based system should be incorporated in the organization, where ethical codes of conduct should be revised after every three months. The top executives should monitor and examine the workplace environment. The line managers and departmental heads should also provide the report to top executives about ethical workplace culture on a monthly basis. Implementing effective policies and right attitude would help in addressing the bullying incidents. Furthermore, the organization would be able to take appropriate actions against the individual violating company's policy. Efforts should be made to improve the workplace culture, so that bullying incidents can be avoided. A satisfied worker or employee can contribute effectively towards the development and growth of the organization.

\section{References}

Aleassa, H. M., \& Megdadi, O. D. (2014). Workplace bullying and unethical behaviors: A mediating model. International Journal of Business and Management, 9(3), 157. https://doi.org/10. 5539/ijbm.v9n3p157

Baillien, E., Neyens, I., De Witte, H., \& De Cuyper, N. (2009). A qualitative study on the development of workplace bullying: Towards a three way model. Journal of Community \& Applied Social Psychology, 19(1), 1-16. https://doi.org/10.02/casp.977

Beale, D., \& Hoel, H. (2011). Workplace bullying and the employment relationship: exploring questions of prevention, control and context. Work, employment and society, 25(1), 5-18.

Bowling, N. A., \& Beehr, T. A. (2006). Workplace harassment from the victim's perspective: A theoretical model and meta-analysis. Journal of Applied Psychology, 91(5), 998-1012. https://doi.org/10.1037/0021-9010.91.5.998

D’Cruz, P. (2014). Workplace bullying in India. Routledge.

D'Cruz, P., \& Noronha, E. (2010). The exit coping response to workplace bullying: The contribution of inclusivist and exclusivist HRM strategies. Employee Relations, 32(2), 102-120. https://doi.org/10.1108/01425451011010078

Desrumaux, P., Machado, T., Przygodzki-Lionet, N., \& Lourel, M. (2015). Workplace Bullying and Victims' Prosocial or Antisocial Behaviors: What Are the Effects on Equity, 
Responsibility Judgments, and Help Giving?. Journal of Human Behavior in the Social Environment, 25(6), 509-521.

Einarsen, S., Hoel, H., \& Cooper, C. (Eds.). (2003). Bullying and emotional abuse in the workplace: International perspectives in research and practice. CRC Press.

Ferris, P. (2004). A preliminary typology of organisational response to allegations of workplace bullying: see no evil, hear no evil, speak no evil. British Journal of Guidance \& Counselling, 32(3), 389-395. https://doi.org/10.1080/03069880410001723576

Ferris, P. (2009). The role of the consulting psychologist in the prevention, detection, and correction of bullying and mobbing in the workplace. Consulting Psychology Journal: Practice and Research, 61(3), 169-189. http://doi.org/10.1037/a0016783

Fox, S., \& Cowan, R. L. (2015). Revision of the workplace bullying checklist: the importance of human resource management's role in defining and addressing workplace bullying. Human Resource Management Journal, 25(1), 116-130.

Griffin, C. (2007). Being dead and being there: research interviews, sharing hand cream and the preference for analysing 'naturally occurring data'. Discourse Studies, 9(2), 246-269. https://doi.org/10.1177/1461445607075340

Glambek, M., Skogstad, A., \& Einarsen, S. (2018). Workplace bullying, the development of job insecurity and the role of laissez-faire leadership: A two-wave moderated mediation study. Work \& Stress, 1-16. https://doi.org/10.1080/02678373.2018.1427815

Guest, G., Bunce, A., \& Johnson, L. (2006). How many interviews are enough? An experiment with data saturation and variability. Field Methods, 18(1), 59-82. https://doi.org/10.1177/1525822X05279903

Harlos, K. P. (2001). When organizational voice systems fail: more on the deaf-ear syndrome and frustration effects. Journal of Applied Behavioral Science, 37(3), 324-342. https://doi.org/10.1177/0021886301373005

Harrington, S., Warren, S., \& Rayner, C. (2015). Human resource management practitioners' responses to workplace bullying: cycles of symbolic violence. Organization, 22(3), 368-389.

Hewett, R., Liefooghe, A., Visockaite, G., \& Roongrerngsuke, S. (2018). Bullying at work: Cognitive appraisal of negative acts, coping, wellbeing, and performance. Journal of occupational health psychology, 23(1), 71.

Hutchinson, M., \& Jackson, D. (2015). The construction and legitimation of workplace bullying in the public sector: insight into power dynamics and organisational failures in health and social care. Nursing inquiry, 22(1), 13-26. https://doi.org/10.1111/nin.12077

Keashly, L. (2001). Interpersonal and systematic aspects of emotional abuse at work: The target's perspective. Violence \& Victims, 16(3), 233-268.

Keashly, L., \& Jagatic, K. (2003). By any other name: American perspectives on workplace bullying. In S. Einarsen, H. Hoel, D. Zapf, \& C. L. Cooper (Eds.), Bullying and emotional 
abuse in the workplace: International perspectives in research and practice (pp. 31-61). London: Taylor \& Francis.

Liefooghe, A. P., \& MacKenzie Davey, K. (2010). The language and organization of bullying at work. Administrative Theory \& Praxis, 32(1), 71-95.

https://doi.org/10.2753/ATP1084-1806320104

Lutgen-Sandvik, P. (2008). Intensive remedial identity work: Responses to workplace bullying, trauma and stigmatization. Organization, 15(1), 97-119. https://doi.org/10.1177/1350508407084487

Magee, C., Gordon, R., Robinson, L., Reis, S., Caputi, P., \& Oades, L. (2015). Distinct workplace bullying experiences and sleep quality: A person-centred approach. Personality and Individual Differences, 87, 200-205.

Mikkelsen, E. G. (2003).Individual effects of exposure to bullying at work. In S. Einarsen, H. Hoel, D. Zapf, \& C. L. Cooper (Eds.), Bullying and emotional abuse in the workplace: International perspectives in research and practice (pp. 127-144). London: Taylor \& Francis.

Parzefall, M-R., \&Salin, D. (2010). Perceptions of and reactions to workplace bullying: A social exchange perspective. Human Relations, 63(6), 761-780.

https://doi.org/10.1177/0018726709345043

Rapley, T. J. (2001). The art (fulness) of open-ended interviewing: some considerations on analysing interviews. Qualitative Research, 1(3), 303-323.

https://doi.org/10.1177/146879410100100303

Rhodes, C., Pullen, A., Vickers, V. H., Clegg, S. R., \& Pitsis, A. (2010). Violence and workplace bullying: What are an organization's ethical responsibilities. Administrative Theory \& Praxis, 32(1), 96-115. https://doi.org/10.2753/ATP1084-1806320105

Salin, D. (2008). The prevention of workplace bullying as a question of human resource management: Measures adopted and underlying organizational factors. Scandinavian Journal of Management, 24, 221-231. https://doi.org/10.1016/j.scaman.2008.04.004

Salin, D. (2009). Organisational responses to workplace harassment: An exploratory study. Personnel Review, 38(1), 26-44. https://doi.org/10.1108/00483480910920697

Silverman, D. (2005). Doing qualitative analysis: A practice Handbook. London:Sage.

Vickers, M. H. (2006). Towards employee wellness: Rethinking bullying paradoxes and masks. Employee Responsibilities \& Rights Journal, 18, 267-281. https://doi.org/10.1007/s10672-006-9023-x

Willig, C. (2008a). Introducing Qualitative Research in Psychology. Maidenhead,Berkshire: Open University Press

Zapf, D., \& Einarsen, S. (2005). Mobbing at work: Escalated conflicts in organizations. In S. Fox, \& P. E. Spector (Eds.), Counterproductive work behavior: Investigations of actors and targets (pp. 237-270). Washington: American Psychological Association. https://doi.org/10.1037/10893-010 